\title{
Research Article \\ Effect of Ethyl Oleate Pretreatment on Drying of Ginger: Characteristics and Mathematical Modelling
}

\author{
A. Waheed Deshmukh, ${ }^{1,2}$ Mahesh N. Varma, ${ }^{2}$ Chang Kyoo Yoo, ${ }^{3}$ and Kailas L. Wasewar ${ }^{2,3}$ \\ ${ }^{1}$ Priyadarshini Institute of Engineering and Technology, RTMN University, Nagpur, Maharashtra 440018, India \\ ${ }^{2}$ Advanced Separations and Analytical Laboratory, Department of Chemical Engineering, \\ Visvesvaraya National Institute of Technology (VNIT), Nagpur Maharashtra 440011, India \\ ${ }^{3}$ Environmental Management \& Systems Engineering Lab (EMSEL), Department of Environmental Science and Engineering, \\ College of Engineering, Kyung Hee University, Seocheon-dong 1, Giheung-gu, Yongin-Si, Gyeonggi-Do 446-701, Republic of Korea
}

Correspondence should be addressed to Chang Kyoo Yoo; ckyoo@khu.ac.kr and Kailas L. Wasewar; k_wasewar@rediffmail.com

Received 30 May 2013; Revised 6 September 2013; Accepted 22 September 2013

Academic Editor: Dr. Sevgi Kolaylı

Copyright (C) 2013 A. Waheed Deshmukh et al. This is an open access article distributed under the Creative Commons Attribution License, which permits unrestricted use, distribution, and reproduction in any medium, provided the original work is properly cited.

\begin{abstract}
Ginger is of high value and export oriented commodity crop, which plays an important role in agricultural sector. Proper drying techniques are required to capitalize this crop. In the present study, the effect of chemical pretreatment of alkaline ethyl oleate on drying behaviour of ginger was investigated and compared with untreated ginger at selected temperatures of 45,55 , and $65^{\circ} \mathrm{C}$ at a constant air velocity of $1.8 \mathrm{~m} / \mathrm{s}$. The drying rate curves showed that drying occurred in falling rate period and the drying times of pretreated ginger were shorter than those of untreated ginger. Thin-layer drying models such as Newton, Page, Modified Page, Henderson and Pabis, and Wang and Singh were evaluated based on statistical criteria. The Page model was found to be a better model for describing the drying kinetics of the ginger. The rehydration capacity of pretreated sample was more than that of untreated sample and increased with drying temperature. The transport of water during drying was temperature dependent and described by Fick's equation. The effective diffusivity varied from $3.87 \times 10^{-10}$ to $1.55 \times 10^{-9} \mathrm{~m}^{2} / \mathrm{s}$ and $4.43 \times 10^{-10}$ to $1.89 \times 10^{-9} \mathrm{~m}^{2} / \mathrm{s}$ with drying temperature for untreated and pretreated ginger slices, respectively.
\end{abstract}

\section{Introduction}

Ginger is an herbaceous perennial plant known as Zinger officinale and belongs to the order Scitamineae and the family Zingiberaceae. It is one of the earliest known oriental spices and is considered as an important cash crop of the world. Ginger is being cultivated as fresh vegetable and as a dried spice. The ginger family is a tropical group, especially abundant in Indo-Malaysian region, consisting of more than 1200 plant spices in 53 genera [1]. Ginger is used in different forms such as raw ginger, dry ginger, bleached dry ginger, ginger powder, ginger oil, ginger oleoresin, brined ginger, and many more. Ginger and its products have varied applications in culinary preparation, bakery products, toiletry products, perfume industries, meat products, wine, and soft drinks making. Dried ginger is used both as a spice and medicine. It contains an essential oil, which imparts an aroma, an oleoresin (gingering) responsible for the pungent smell, starch, gums, proteins, carbohydrate, mineral matter, and fiber [2]. In Ayurveda, it is termed as an important medicine to cure many diseases, such as, rheumatism, piles, dyspepsia, alcoholic gastritis, fabric disease, throat problems, cholera morbus, neuralgia, pulmonary and catarrhal diseases.

Drying has a vital role in postharvest processing. It has always been of great importance for conserving agricultural products and for extending the food shelf life [3]. The removal of moisture prevents the growth and reproduction of micro-organisms causing decay and minimizes many of the moisture-mediated deterioration reactions. It brings about substantial reduction in weight and volume, minimizing packing, storage, and transportation costs and enables storability of the product under ambient temperatures [4]. Open sun drying is being practiced in many urban and rural areas which is a time consuming method. The major disadvantage 
of this conventional technique is low quality and hygienic problems. The product gets contaminated from dust, insects, rodents, and other animals, thus seriously degrading the food quality ultimately resulting in a negative trade potential and economical worth. Varieties of mechanical energy driven dryers are developed for preventing the deterioration of products and for reducing the drying time.

Drying of fruits and vegetables is one of the most time and energy consuming processes. Drying rate must be accelerated to reduce the drying process and energy consumption without compromising the quality. One of the major obstacles in removing the moisture from the material is the outer layer of the material, the skin. It acts as the major resistance to the moisture transport from interior of the material to surface. Pretreatment is an essential step before processing of food materials to overcome this problem up to great extent. It has been reported that pretreatments can accelerate the drying rate by dissociating the wax and forming the fine cracks on the surface of the material for easy moisture removal. Pretreatments also improve the quality of dehydrated product by expelling intercellular air from the tissues, softening the texture, and destroying the enzymes and micro-organisms in the product. Pretreatments are broadly classified as thermal, mechanical, and chemical and some newly proposed such as using electro-technologies. Thermal pretreatments include steaming, blanching, autoclaving, and freezing of the material while mechanical pretreatments are peeling, cutting the product in to definite shapes, surface skin abrasion, and application of high pressure. Some of the electro-pretreatments are use of pulsed electric field of varying intensities and pulse values, ultrasound, and Ohmic pretreatments. The basic intention of these techniques is to accelerate the drying rate by affecting the surface to facilitate the moisture removal. Chemical pretreatments involve the immersion of the product in acidic, alkaline, oleate esters or other chemicals for definite time duration prior to drying. Chemical pretreatments influence the skin of the produce and improve the subsequent water removal by forming fine cracks and dissociating the wax platelets on the surface. Many researchers have investigated the effect of this different pretreatments on various fruits, vegetables, and other food drying. The study of effect of blanching on the rate of moisture movement during drying of strawberries enhanced the effective moisture diffusivity remarkably [5]. The drying time of pre-treated plums using chemical pretreatment was observed to be significantly shorter than that of untreated samples of plums [6]. It was found that chemical pretreatment could significantly accelerate the drying process and remarkably improve the quality of red peppers undergoing greenhouse and open sun drying [7]. The pretreatment of blanching and calcium impregnation proved that blanching pretreatment strongly improved the drying rate of apple slices [8]. Most of the food products are generally covered with the thin layer of wax cuticles. To accelerate the drying rate chemical treatments such as immersion of the product in alkaline or acid solutions, oleate esters or other chemicals prior to the drying are generally practiced. The main idea is to influence the skin of the produce and to ease the moisture removal. Alkaline dipping facilitates drying by forming fine cracks on the skin, and dipping in oleate esters causes the wax platelets on the fruit skin to dissociate and favour the moisture removal [9]. Chemical pretreatment such as ethyl oleate was found to be suitable for improving the drying rate and therefore increasing drying speed but has little effect on product quality of strawberry [3]. The effects of pretreatment solution on some fruits such as strawberry, apricot, and cranberries were studied before drying so as to remove the wax cuticle and increased their permeability to water $[3,10$, $11]$.

However, there is limited information on the effects of chemical pretreatment of alkaline ethyl oleate dipping on drying of ginger in the literature. The present work deals with the study of drying behaviour of ginger with and without pretreatment in tray dryer at different drying temperatures. It includes investigation of effect of pretreatment of alkaline ethyl oleate solution on drying time, drying rate, rehydration capacity, evaluation of some thin layer drying models, and determination of effective diffusivity.

\section{Materials and Methods}

Fresh ginger was purchased from local market of Nagpur India, and washed thoroughly to remove surface dust and extraneous matter under running water. The clean ginger was hand peeled by knife and cut into thin slices of average thickness of $2.5 \pm 0.5 \mathrm{~mm}$ with slicer. The slices were kept at ambient for one hour to remove surface moisture. The initial moisture content of fresh ginger was determined by standard lab oven method with three replicates and found to be 621.50 to 650.00 (\% d.b.). Ethyl oleate and potassium carbonate were obtained from Merck (Germany).

2.1. Experimental. The drying of ginger was investigated in a laboratory cabinet tray dryer. The dryer consists of centrifugal blower, electric heater, drying chamber, and proportional temperature controller. The hot air velocity at exit was measured by Omega HHF81 probe Anemometer (Canada) with a precision of $( \pm 4 \%)$. The samples were dried on the perforated tray $22.5 \mathrm{~cm} \times 17.1 \mathrm{~cm}$.

After washing the ginger slices with tap water, pretreatment of alkaline ethyl oleate solution $\left(2 \% \mathrm{EO}+5 \% \mathrm{~K}_{2} \mathrm{CO}_{3}\right.$, coded as AEEO) was given by dipping the whole samples at room temperature for $1 \mathrm{~min}$. The untreated samples (coded as NAT) were just washed with tap water to remove dirt and dust matters before drying. The drying experiments of pretreated and untreated ginger were performed at the selected temperatures of 45,55 , and $65^{\circ} \mathrm{C}$ with a constant air velocity of $1.8 \mathrm{~m} / \mathrm{s}$. The dryer was charged with accurately measured sample, after running the dryer without load for $45 \mathrm{~min}$ until the steady state temperature was achieved. Weight of the samples was recorded at predetermined time interval. The amount of moisture lost was recorded using digital weighing balance (Wensar make, HPB 310, least count $0.1 \mathrm{gm}$ ) till the constant weight was achieved. The dried dinger slices were packed in low density polyethylene (LDPE) air tight bags after cooling. 
2.2. Rehydration. Rehydration study was carried out by adding $3 \mathrm{~g}$ of dried ginger in $100 \mathrm{~mL}$ distilled water at room temperature $\left(34^{\circ} \mathrm{C} \pm 1^{\circ} \mathrm{C}\right)$ for $24 \mathrm{~h}$. After rehydration, samples were taken out; surface moisture was absorbed carefully with tissue paper and then weighed [1]. The rehydration capacity was calculated as follows [3]:

$$
\text { Rehydration capacity }=\frac{W_{r}}{W_{d}},
$$

where $W_{r}$ is the weight after rehydration $(\mathrm{kg})$ and $W_{d}$ is the weight of dried ginger $(\mathrm{kg})$.

2.3. Mathematical Modelling of Drying. The moisture ratio of ginger during the drying was calculated by using the following equation:

$$
\mathrm{MR}=\frac{M_{t}-M_{e}}{M_{0}-M_{e}},
$$

where, $M_{t}, M_{0}$, and $M_{e}$ are moisture content at any drying time, initial, and equilibrium on dry basis, respectively. The value of equilibrium moisture content is relatively small as compared to $M_{t}$ and $M_{0}$, which shows that the error involved in the simplification is negligible [18]; hence, the moisture ratio was calculated as

$$
\mathrm{MR}=\frac{M_{t}}{M_{0}} .
$$

Drying model selection was done by fitting the drying curves to well-known thin-layer drying models given in Table 1. Best suitability of the model was determined by three statistical criteria, namely, coefficient of determination $\left(R^{2}\right)$, reduced chi-square $\left(\chi^{2}\right)$, and root mean square error (RMSE) described by following equations [19]:

$$
\begin{aligned}
\chi^{2} & =\frac{\sum_{i=1}^{N}\left(\mathrm{MR}_{\mathrm{exp}, i}-\mathrm{MR}_{\mathrm{pr}, i}\right)^{2}}{N-n}, \\
\mathrm{RMSE} & =\frac{1}{N}\left[\sum_{i=1}^{N}\left(\mathrm{MR}_{\mathrm{exp}, i}-\mathrm{MR}_{\mathrm{pre}, i}\right)^{2}\right]^{1 / 2},
\end{aligned}
$$

where $\mathrm{MR}_{\text {exp }, i}$ is the experimental moisture ratio found in any measurement and $\mathrm{MR}_{\text {pre }, i}$ is the predicted moisture ratio for this measurement. $N$ is the number of observations and $n$ is the number of constants in drying model. The best model was chosen as the one with the highest coefficient of determination, least reduced chi-square, and root mean square error.

2.4. Diffusivity. Diffusion is the most likely physical mechanism governing the drying process in falling rate period for food materials [3]. Fick's second diffusion law has been widely used to describe the moisture removal in falling rate periods. The effective diffusivity of the material can be calculated by assuming constant moisture diffusivity, temperature, and negligible shrinkage during drying process using the following equation:

$$
\ln \mathrm{MR}=\ln \left(\frac{8}{\pi^{2}}\right)-\frac{\pi^{2} D_{\mathrm{eff}} t}{L^{2}},
$$

TABLE 1: Mathematical models applied to drying of ginger.

\begin{tabular}{lcc}
\hline Model Name & Model equation & References \\
\hline Newton & $\mathrm{MR}=\exp (-k t)$ & {$[12]$} \\
Page & $\mathrm{MR}=\exp \left(-k t^{n}\right)$ & {$[13,14]$} \\
Henderson and Pabis & $\mathrm{MR}=a \exp (-k t)$ & {$[15]$} \\
Modified Page & $\mathrm{MR}=\exp \left[(-k t)^{n}\right]$ & {$[16]$} \\
Wang and Sing & $\mathrm{MR}=1+a t+b t^{2}$ & {$[17]$} \\
\hline
\end{tabular}

where $D_{\text {eff }}$ is the effective diffusivity, $L$ is the half of the length of ginger slice, and $t$ is the corresponding drying time. The Effective diffusivity can be calculated by plotting experimental moisture as $\ln (\mathrm{MR})$ versus drying time gives a straight line with slope of

$$
\text { Slope }=\frac{\pi^{2} D_{\mathrm{eff}}}{L^{2}}
$$

\section{Results and Discussion}

3.1. Effect of Pretreatment on Drying. Figure 1 shows the effect of pretreatment on drying time of ginger in tray dryer. The moisture ratio of untreated and pre-treated ginger was plotted against drying time at different drying temperatures. The samples dipped in alkaline ethyl oleate solution prior to drying were found to have shorter drying time compared to untreated samples for corresponding temperatures. The drying time required to reduce the initial moisture content from 650 (\% d.b.) to desired final moisture content up to 40 (\% d.b.) for untreated samples at temperatures 45, 55, and $65^{\circ} \mathrm{C}$ was found to be 400,360 , and $300 \mathrm{~min}$ while for pre-treated samples, drying time was found to be 330,300 , and $270 \mathrm{~min}$, respectively. These results demonstrate that the drying time for pre-treated samples reduces up to $17.5 \%$ as compared to untreated samples. AEEO solution is found to be effective for pretreatment of ginger as it is helpful to increase the skin permeability and removes the waxy layer on the surface. Similar results of pretreatment of AEEO solution on drying of strawberry and apricots were found to be efficient $[3,10]$.

As shown in Figure 2, drying rate decreases continuously with decreasing moisture content. This may be due to high amount of free moisture availability, which was easily removed in the initial stage of drying [20]. Drying rates for pre-treated samples were greater as compared to untreated samples for respective temperatures. There was no constant rate period observed, and most of the drying occurs in falling rate period for both untreated and pre-treated ginger for all drying temperatures. This may be due to that material surface was no longer saturated with water and drying rate is controlled by diffusion of moisture from interior of solid to the surface. These results are in agreement with the observations of the earlier researchers based on the thin-layer drying studies $[20,21]$.

3.2. Rehydration Studies. Removal of moisture from cellular structure induced changes in the physical properties of the dried material. The rehydration characteristics of ginger 


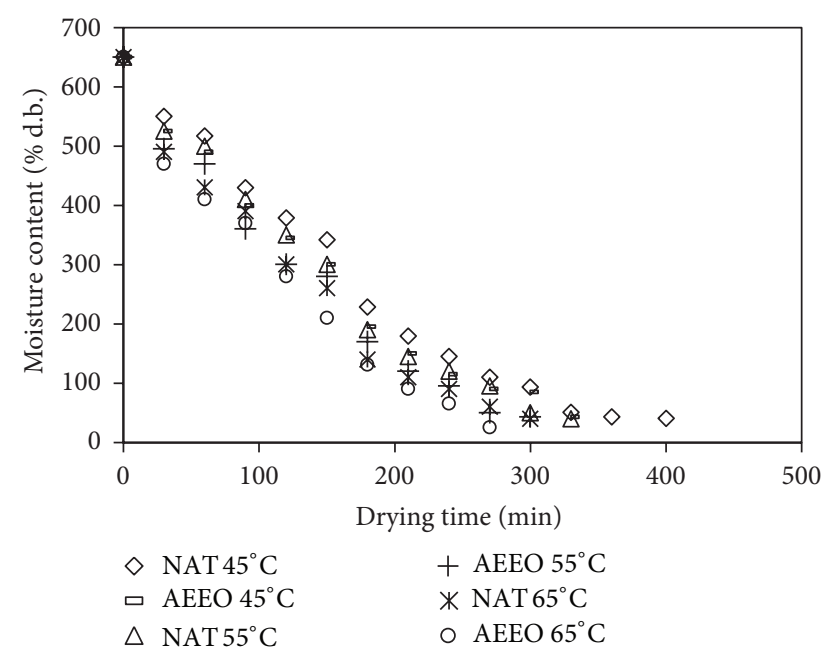

FIGURE 1: Variation of moisture content with drying time for pretreated/untreated ginger.

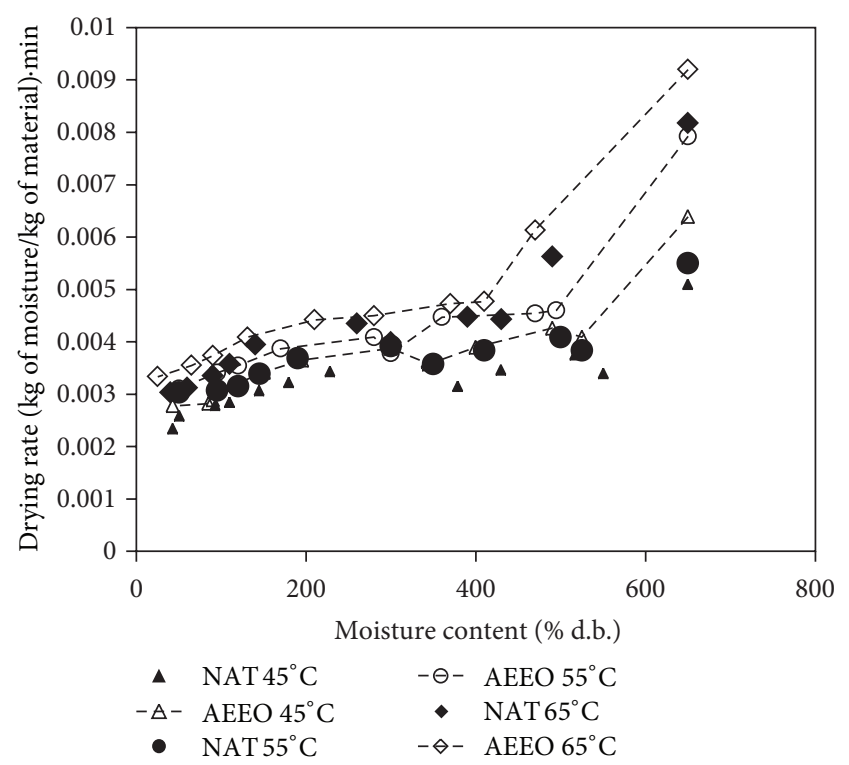

FIGURE 2: Variation of moisture content with drying rate for pretreated/untreated ginger at different temperatures.

samples dried at different air temperatures are illustrated in Figure 3. It showed that ginger flakes have significant rehydration capacity. Rehydration capacity of ginger flakes dried at lower temperature was lesser as compared to the sample dried at higher temperature. The rehydration capacity was found to be more and faster at $65^{\circ} \mathrm{C}$ than other temperatures for both pre-treated and untreated samples. Rehydration capacity of pre-treated sample was found to be greater than untreated sample for the respective temperatures. This ensures that the pretreatment yields more compact structure after drying process [3].

3.3. Modeling of Drying Curves. The regression analysis was done by relating the drying time and dimensionless moisture

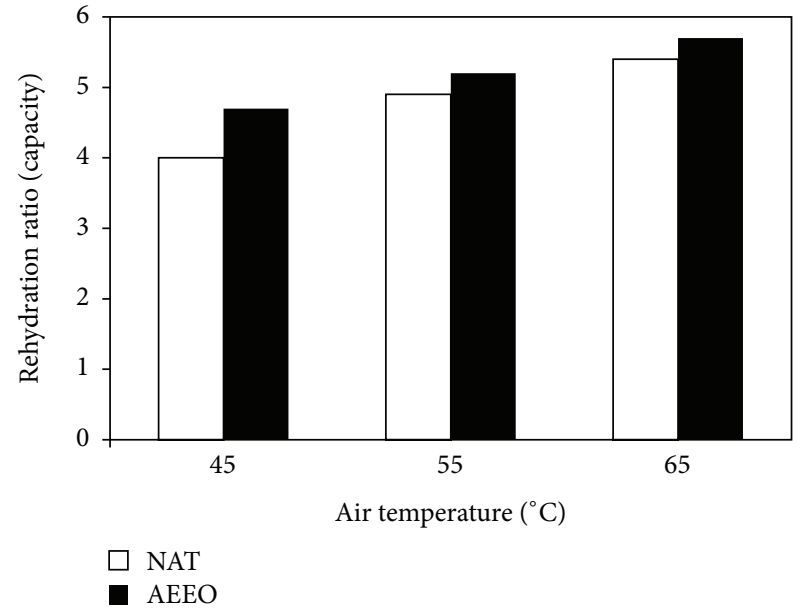

FIGURE 3: Rehydration ratio of pre-treated/untreated samples at different temperatures.

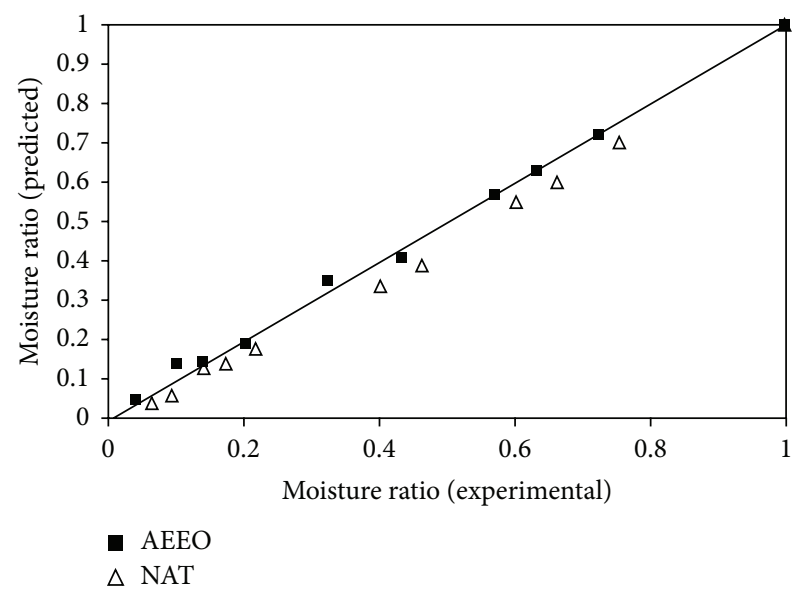

FIGURE 4: Variation of moisture ratio for pre-treated/untreated samples for ginger using Page model at $65^{\circ} \mathrm{C}$.

ratio for five thin-layer drying models. The suitability of the model was decided based on coefficient of determination $\left(R^{2}\right)$, reduced chi-square $\left(\chi^{2}\right)$, and root mean square error (RMSE). The model coefficients and parameters for untreated and pre-treated samples are presented in Tables 2 and 3. It is observed that the Page model is best suitable to describe the drying kinetics of both untreated and pre-treated ginger. The best $R^{2}, \chi^{2}$, and RMSE values for untreated samples were $0.9890,0.0045$, and 0.0019 while for pre-treated samples, they were found to be $0.9987,0.0008$, and 0.001 , respectively, at $65^{\circ} \mathrm{C}$.

Figure 4 compares the experimental moisture ratio with predicted moisture ratio at $65^{\circ} \mathrm{C}$ by Page model. The result showed smooth and scattered data points around the fitted line. It is observed that the moisture ratio predicted for pretreated samples is fixed more appropriately than untreated sample to straight line. This confirms the suitability of pretreatment to improve the performance of the model to 


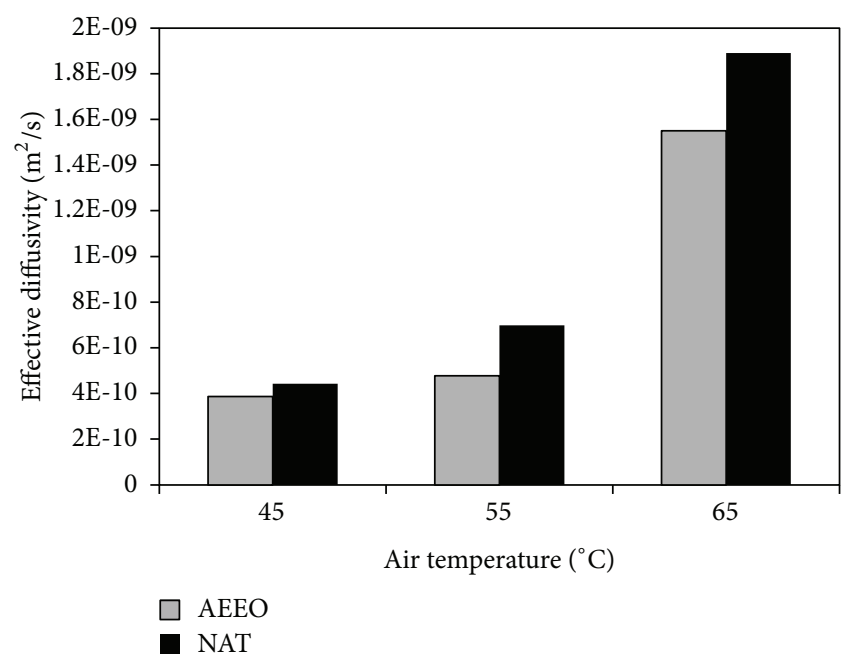

FIGURE 5: Variation of effective diffusivity with drying temperature for of pre-treated/untreated samples.

estimate the moisture content of ginger in drying process for tray drying.

3.4. Effective Diffusivity. The effective diffusivity of pretreated and untreated samples was calculated by plotting $\ln$ (MR) with drying time using (5), where slope of the straight line gives the effective diffusivity of the sample. Finding from this study indicates that there is a direct relationship between temperature and the effective spread, which depicts that increase in temperature leads to increase in the effective distribution coefficient. Temperature of $65^{\circ} \mathrm{C}$ has the highest value of $D_{\text {eff }}$ for both pre-treated and untreated samples. The result of effective diffusivity of pre-treated and untreated samples is summarized in Table 4 . The effective diffusivities varied from $4.43 \times 10^{-10}$ to $1.89 \times 10^{-9} \mathrm{~m}^{2} / \mathrm{s}$ for pre-treated samples and from $3.87 \times 10^{-10}$ to $1.55 \times 10^{-9} \mathrm{~m}^{2} / \mathrm{s}$ for untreated samples over the temperature range $45-65^{\circ} \mathrm{C}$. The value of effective diffusivity is enhanced for each temperature when sample was pre-treated (Figure 5). The results agreed with the finding of other researchers [3].

\section{Conclusions}

The comparative study of ginger tray drying was carried out with and without alkaline ethyl oleate pretreatment at different temperatures. It was found that increase in drying temperature along with alkaline pretreatment of ethyl oleate increases drying rate and consequently decreases drying time. The entire drying process occurred in falling rate periods and no constant rate period was observed. The rehydration capacity of pre-treated samples was more than that of untreated samples, and rehydration capacity increases with increase in drying temperature for both pre-treated and untreated samples. Drying kinetics of ginger were evaluated by testing five different drying models. Comparative study of coefficient of determination $\left(R^{2}\right)$, reduced chi-square value $\left(\chi^{2}\right)$, and root mean square error (RMSE) shows that the
TABLE 2: Statistical results from various tested thin-layer drying models for untreated ginger.

\begin{tabular}{ccccc}
\hline$T\left({ }^{\circ} \mathrm{C}\right)$ & Model name & $R^{2}$ & $\chi^{2}$ & RMSE \\
\hline \multirow{4}{*}{45} & Newton & 0.9269 & 0.008 & 0.0606 \\
& Page & $\mathbf{0 . 9 8 2 3}$ & $\mathbf{0 . 0 0 5 3 8}$ & $\mathbf{0 . 0 3}$ \\
& Henderson and Pabis & 0.9638 & 0.0014 & 0.049 \\
& Wang and Sing & 0.9462 & 0.00731 & 0.068 \\
& Modified Page & 0.9753 & 0.0055 & 0.0534 \\
\hline \multirow{4}{*}{55} & Newton & 0.9345 & 0.0073 & 0.01 \\
& Page & $\mathbf{0 . 9 8 7 8}$ & $\mathbf{0 . 0 0 5}$ & $\mathbf{0 . 0 0 2 3}$ \\
& Henderson and Pabis & 0.9344 & 0.0045 & 0.054 \\
& Wang and Sing & 0.9510 & 0.00654 & 0.0054 \\
& Modified Page & 0.967 & 0.007 & 0.0534 \\
\hline \multirow{4}{*}{$65 \quad$ Newton } & 0.94321 & 0.0067 & 0.09 \\
& Page & $\mathbf{0 . 9 8 9 0}$ & $\mathbf{0 . 0 0 4 5}$ & $\mathbf{0 . 0 0 1 9}$ \\
& Henderson and Pabis & 0.9123 & 0.0093 & 0.065 \\
& Wang and Sing & 0.9623 & 0.00540 & 0.0047 \\
& Modified Page & 0.9723 & 0.0054 & 0.0435 \\
\hline
\end{tabular}

Bold font indicates the betterment of Page model to explain the thin layer drying kinetics among the other tested models based on statistical criteria.

TABLE 3: Statistical results from various thin-layer drying models for pretreated ginger.

\begin{tabular}{ccccc}
\hline$T\left({ }^{\circ} \mathrm{C}\right)$ & Model name & $R^{2}$ & $\chi^{2}$ & RMSE \\
\hline \multirow{4}{*}{45} & Newton & 0.9363 & 0.0073 & 0.0507 \\
& Page & $\mathbf{0 . 9 8 8 2}$ & $\mathbf{0 . 0 0 4 3 5}$ & $\mathbf{0 . 0 2 8}$ \\
& Henderson and Pabis & 0.954 & 0.0017 & 0.054 \\
& Wang and Sing & 0.9567 & 0.00657 & 0.061 \\
& Modified Page & 0.9823 & 0.0041 & 0.0434 \\
\hline \multirow{4}{*}{$55 \quad$ Newton } & 0.943 & 0.0065 & 0.0912 \\
& Page & $\mathbf{0 . 9 9 1 2}$ & $\mathbf{0 . 0 0 4 1}$ & $\mathbf{0 . 0 0 1 3}$ \\
& Henderson and Pabis & 0.9789 & 0.0041 & 0.048 \\
& Wang and Sing & 0.9812 & 0.00543 & 0.0047 \\
& Modified Page & 0.9882 & 0.0037 & 0.038 \\
\hline \multirow{4}{*}{$65 \quad$ Newton } & 0.9567 & 0.00612 & 0.087 \\
& Page & $\mathbf{0 . 9 9 8 7}$ & $\mathbf{0 . 0 0 0 8}$ & $\mathbf{0 . 0 0 1}$ \\
& Henderson and Pabis & 0.9812 & 0.0054 & 0.054 \\
& Wang and Sing & 0.9756 & 0.00400 & 0.0042 \\
& Modified Page & 0.989 & 0.0034 & 0.031 \\
\hline
\end{tabular}

Bold font indicates the betterment of Page model to explain the thin layer drying kinetics among the other tested models based on statistical criteria.

TABLE 4: Calculated effective moisture diffusivity for pre-treated and untreated ginger for different drying temperatures.

\begin{tabular}{lcc}
\hline Code & Air temperature $T\left({ }^{\circ} \mathrm{C}\right)$ & Effective diffusivity, $D_{\text {eff }}\left(\mathrm{m}^{2} / \mathrm{sec}\right)$ \\
\hline \multirow{3}{*}{ NAT } & 45 & $3.87 \times 10^{-10}$ \\
& 55 & $4.78 \times 10^{-10}$ \\
& 65 & $1.55 \times 10^{-9}$ \\
\hline \multirow{3}{*}{ AEEO } & 45 & $4.43 \times 10^{-10}$ \\
& 55 & $6.98 \times 10^{-10}$ \\
& 65 & $1.89 \times 10^{-9}$ \\
\hline
\end{tabular}

Page model is best described the thin-layer drying of ginger for both pre-treated and untreated ginger in tray dryer. The 
Page model attained the highest value of $R^{2}$, the lowest value of $\chi^{2}$, and RMSE $\left(R^{2}=0.9987, \chi^{2}=0.0008\right.$, and $\mathrm{RMSE}=0.001)$ for pre-treated samples at $65^{\circ} \mathrm{C}$. The effective diffusivity increases with increase in drying temperature and further shows enhancement when the samples were pretreated.

\section{References}

[1] H. Rahman, R. Karuppaiyan, K. Kishor, and R. Denzongpa, "Traditional practices of ginger cultivation in Northeast India," Indian Journal of Traditional Knowledge, vol. 8, no. 1, pp. 23-28, 2009.

[2] K. K. Singh, D. Tiroutchelvame, and S. Patel, "Drying characteristics of ginger flakes," in Proceeding of 16th International Drying Symposium (IDS '08), pp. 1383-1386, Hydrabad, India, 2008.

[3] İ. Doymaz, "Convective drying kinetics of strawberry," Chemical Engineering and Processing, vol. 47, no. 5, pp. 914-919, 2008.

[4] K. S. Jayaraman, D. K. Das Gupta, and A. S. Mujumdar, Handbook of Industrial Drying, vol. 1, Marcel Dekker, New York, NY, USA, 1995.

[5] C. A. Alvarez, R. Aguerre, R. Gómez, S. Vidales, S. M. Alzamora, and L. N. Gerschenson, "Air dehydration of strawberries: effects of blanching and osmotic pretreatments on the kinetics of moisture transport," Journal of Food Engineering, vol. 25, no. 2, pp. 167-178, 1995.

[6] İ. Doymaz, "Effect of dipping treatment on air drying of plums," Journal of Food Engineering, vol. 64, no. 4, pp. 465-470, 2004.

[7] G. Ergüneş and S. Tarhan, "Color retention of red peppers by chemical pretreatments during greenhouse and open sun drying," Journal of Food Engineering, vol. 76, no. 3, pp. 446-452, 2006.

[8] M. González-Fésler, D. Salvatori, P. Gómez, and S. M. Alzamora, "Convective air drying of apples as affected by blanching and calcium impregnation," Journal of Food Engineering, vol. 87, no. 3, pp. 323-332, 2008.

[9] K. Venkatachalapathy and G. S. V. Raghavan, "Microwave drying of osmotically dehydrated blueberries," Journal of Microwave Power and Electromagnetic Energy, vol. 33, no. 2, pp. 95-102, 1998.

[10] İ. Doymaz, "Effect of pre-treatments using potassium metabisulphide and alkaline ethyl oleate on the drying kinetics of apricots," Biosystems Engineering, vol. 89, no. 3, pp. 281-287, 2004.

[11] P. S. Sunjka and G. S. V. Raghavan, "Assessment of pretreatment methods and osmotic dehydration for cranberries," Canadian Biosystems Engineering, vol. 46, pp. 3.35-3.40, 2004.

[12] W. K. Lewis, "The rate of drying of solid materials," Journal of Industrial Engineering and Engineering Chemistry, vol. 13, pp. 427-432, 1921.

[13] G. Page, Factors influencing the maximum rates of air drying shelled corn in thin layers [M.S. thesis], Purdue University, 1949.

[14] S. Simal, A. Femenia, M. C. Garau, and C. Rosselló, "Use of exponential, Page's and diffusional models to simulate the drying kinetics of kiwi fruit," Journal of Food Engineering, vol. 66, no. 3, pp. 323-328, 2005.

[15] S. M. Henderson and S. Pabis, "Grain drying theory I: temperature effect on drying coefficient," Journal of Agricultural Engineering Research, vol. 6, pp. 169-174, 1961.
[16] Z. Wang, J. Sun, X. Liao et al., "Mathematical modeling on hot air drying of thin layer apple pomace," Food Research International, vol. 40, no. 1, pp. 39-46, 2007.

[17] C. Y. Wang and R. P. Singh, "A single layer drying equation for rough rice," American Society of Agricultural Engineers, paper No. 78-3001: St. Joseph, Mich, USA, 1978.

[18] R. K. Goyal, A. R. P. Kingsly, M. R. Manikantan, and S. M. Ilyas, "Mathematical modelling of thin layer drying kinetics of plum in a tunnel dryer," Journal of Food Engineering, vol. 79, no. 1, pp. 176-180, 2007.

[19] I. T. Togrul and D. Pehlivan, "Mathematical modelling of solar drying of apricots in thin layers," Journal of Food Engineering, vol. 55, no. 3, pp. 209-216, 2002.

[20] T. Garware, N. Sutar, and B. Thorat, "Drying of tomato using different drying methods: comparison of drying kinetics and rehydration ratio," in Proceeding of 16th International Drying Symposium (IDS '2008), pp. 1427-1432, Hydrabad, India, 2008.

[21] C. Ertekin and O. Yaldiz, "Drying of eggplant and selection of a suitable thin layer drying model," Journal of Food Engineering, vol. 63, no. 3, pp. 349-359, 2004. 

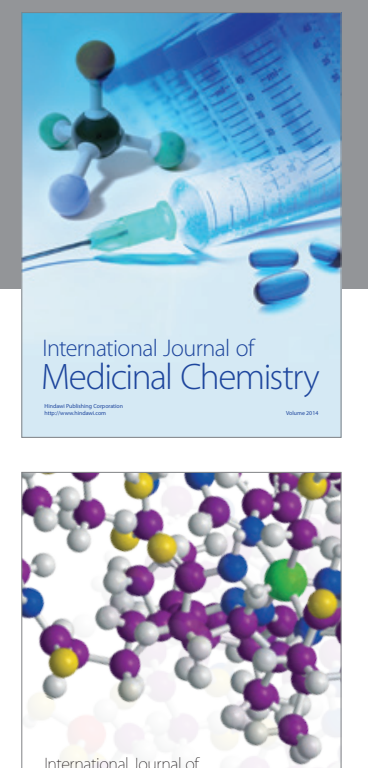

\section{Carbohydrate} Chemistry

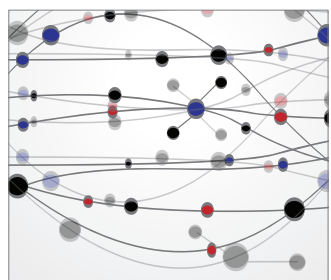

The Scientific World Journal
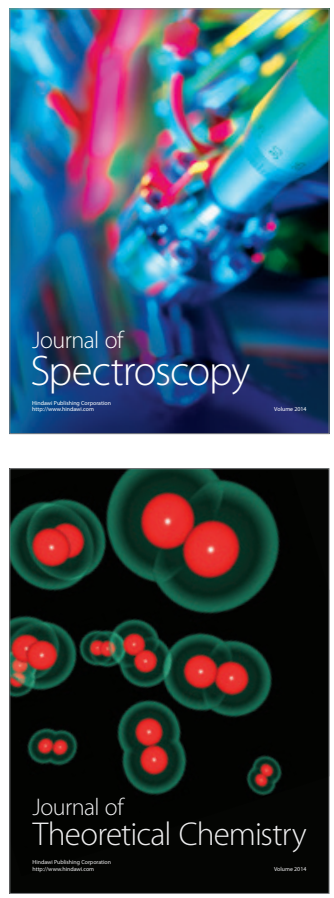
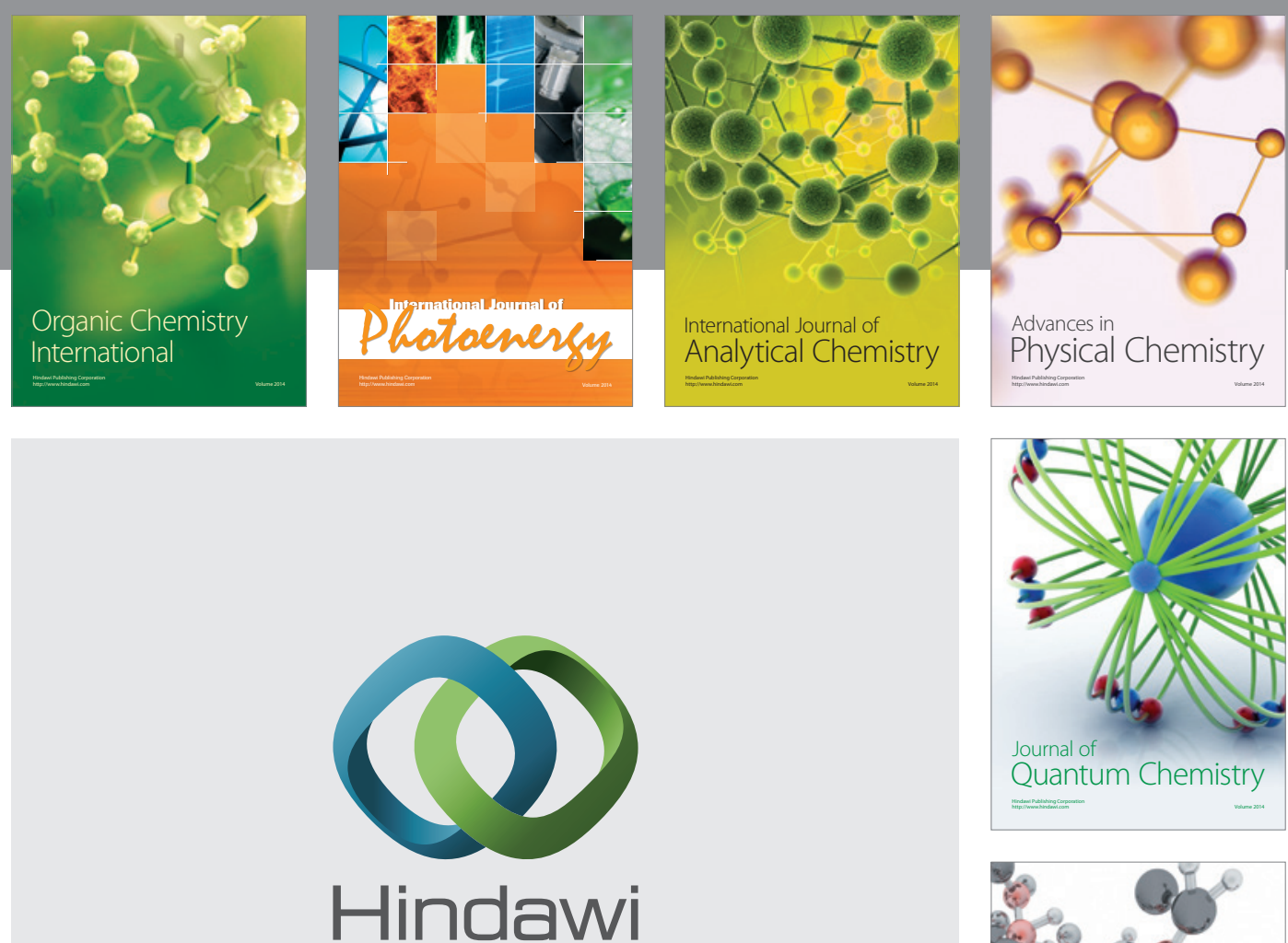

Submit your manuscripts at

http://www.hindawi.com

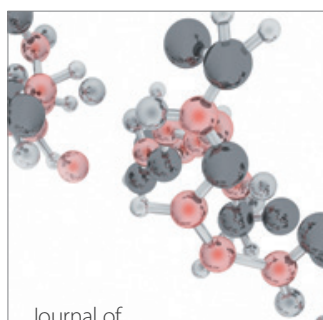

Analytical Methods

in Chemistry

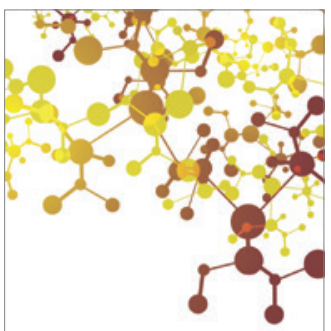

Journal of

Applied Chemistry

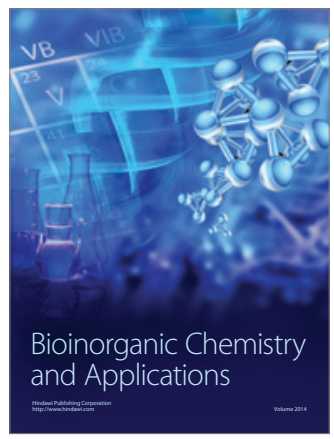

Inorganic Chemistry
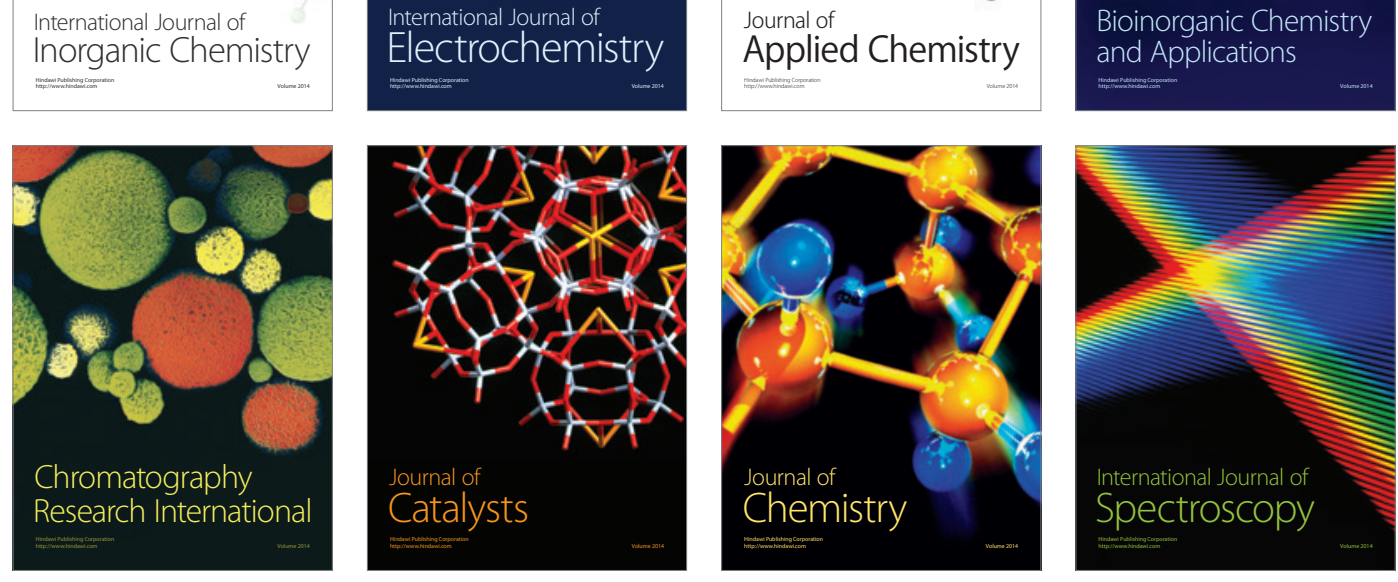